\title{
Leere Praxen in den Städten - Wartezeiten auf dem Land
}

In den Städten in der Schweiz haben immer mehr Arztpraxen zu wenige Patienten: Fast die Hälfte der städtischen Praxen bleibt an mindestens einem Tag in der Woche leer, hat die Schweizerische Zahnärzte-Gesellschaft (SSO) in einer Befragung von fast 1400 ihrer Mitglieder herausgefunden. Die Praxen in kleineren Ortschaften hingegen seien gut ausgelastet. Verkehrte Welt zu den deutschen Verhältnissen könnte man annehmen, doch so ist es nicht ganz: Die Städte in der Schweiz sind im Gegensatz zu den ländlichen Gebieten und Orten mit Zahnärzten überversorgt. Die SSO führt dies auf den Zuzug ausländischer Zahnärzte zurück, die größtenteils in den Städten praktizierten und die Konkurrenz verschärften. Seit dem Jahr 2002, als die entsprechenden Verträge in Kraft getreten sind, ließen demnach mehr als 4600 Zahnärzte aus Ländern der Europäischen Union, EFTA- oder Drittstaaten ihre Diplome in der Schweiz anerkennen. 31 Prozent der befragten SSO-Zahnärzte praktizieren der Umfrage zufolge in Städten mit mehr als 50.000
Einwohnern, die Hälfte von ihnen kann ihre Praxis nur zu 80 Prozent oder weniger auslasten. In kleineren und mittleren Orten hingegen können Zahnärzte ihren Patienten nicht immer kurzfristige Termine anbieten.

sas

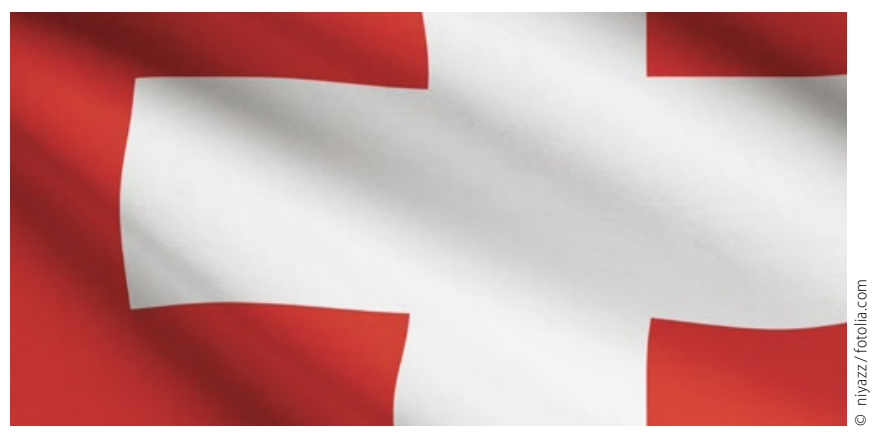

\section{Gemeinsames Engagement von Zahnärzten und Bundeswehr in Niedersachsen}

\section{Zahnstation für Flüchtlinge im ehemaligen NATO-Camp eröffnet}

Norddeutschlands größte Erstaufnahmeeinrichtung für Flüchtlinge hat jetzt eine eigene Zahnstation. Im einstigen NATOCamp in Oerbke bei Bad Fallingbostel, in dem mehrere tausend Menschen nach ihrer Flucht ein vorübergehendes Zuhause gefunden haben, haben engagierte Zahnärzte mit Hilfe der Bundeswehr und des Landes Niedersachsen das ehemalige „Dental Centre" der britischen Streitkräfte umgebaut, neu eingerichtet und wieder in Betrieb genommen. Die Idee dazu hatte der Fallingbosteler Zahnarzt Dr. Julius Beischer, der sich daran erinnerte, dass die britische Armee einst ihr eigenes „Medical Centre" betrieben hatte. Es war ein organisatorischer und bürokratischer Kraftakt, doch entstanden ist nun eine vollwertige, mo-

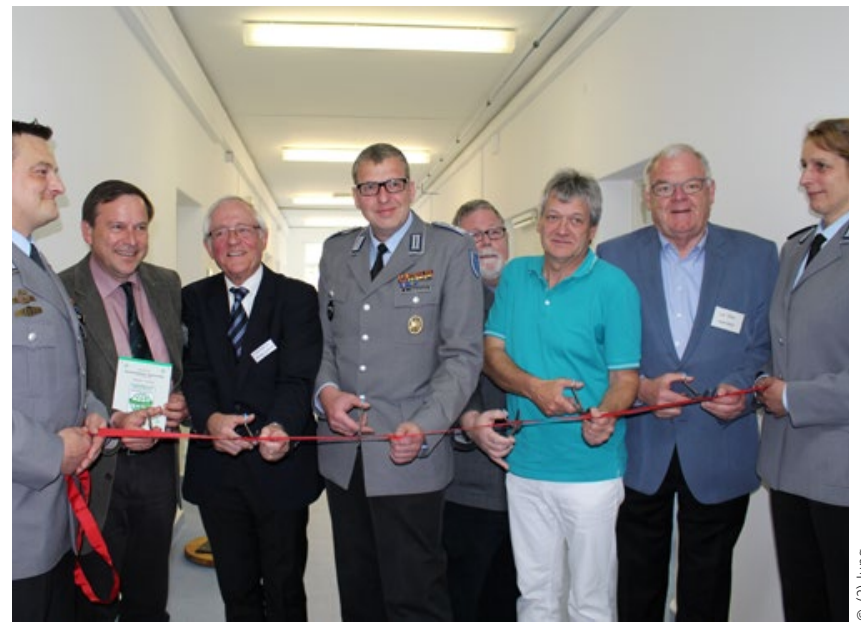

Hand in Hand: Zahnärzte, Bundeswehr und Sponsoren (nicht nur) bei der Eröffnung der Zahnstation im ehemaligen britischen Camp. derne Zahnarztpraxis. In den beiden Behandlungsräumen versorgen inzwischen sowohl zivile als auch Zahnärzte der Bundeswehr gemeinsam die Patienten. Die Einrichtung der Zahnstation, des Röntgen- und Sterilisationsbereichs wurde von der Zahnärzteschaft, dem Hilfswerk Deutscher Zahnärzte und einer niedersächsischen Dentalfirma gespendet.

Die zahnärztliche Versorgung vor Ort im Camp hat nicht nur Vorteile für die Patienten, sondern auch für die umliegenden Zahnarztpraxen im Heidekreis: Bisher wurden die Patienten per Taxi zu nächstgelegenen Praxen gefahren, wenn eine Schmerzbehandlung notwendig war. Nicht nur diese Kosten werden künftig gespart, sondern auch die Zahnarztpraxen rundum entlastet. sas

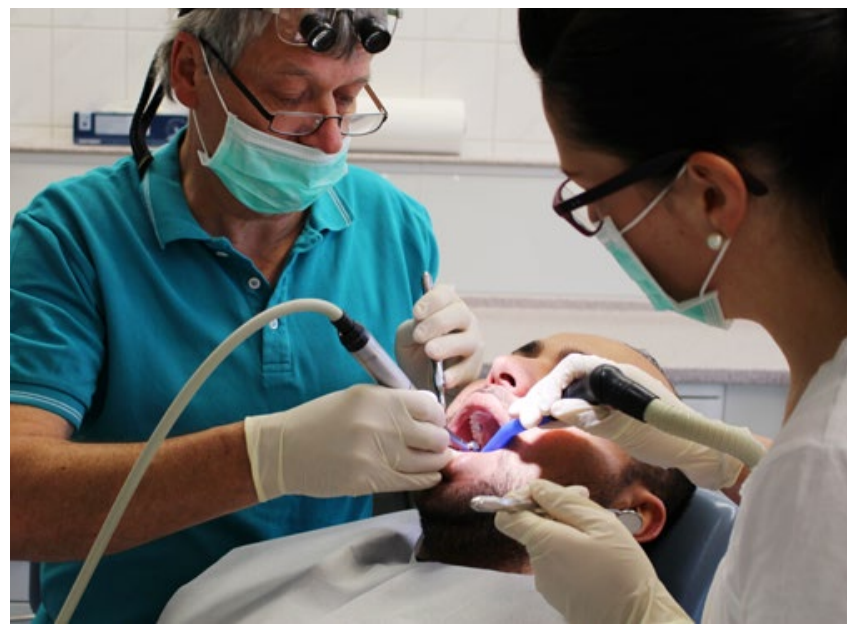

Engagiert beim Aufbau der Zahnstation und bei der Behandlung: Zahnarzt Frank Jagade mit seiner Helferin. 